\title{
Metanephric Rat-Mouse Chimeras to Study Cell Lineage of the Nephron
}

\author{
LOIS J . AREND, ${ }^{1 *}$ ANN SMART, ${ }^{2}$ AND J OSIE P. BRIGGS ${ }^{2}$ \\ 'Department of Pathology, U niversity of Michigan, Ann Arbor, Michigan \\ ${ }^{2}$ NIDDK, NIH, Bethesda, Maryland
}

\begin{abstract}
The nephron is derived from the ureteric bud and metanephric mesenchyme and develops into a complex epithelial structure with a wide variety of phenotypes along its length. This segmental variation in expression of molecules provides an approach to understand the lineage of unique segments. The present study evaluated the expression of four relatively well-localized molecules - renin, TammHorsfall protein (THP), oxytocin receptor (OTR), and the vasopressin type 2 receptor (V2R) - in cultured mouserat chimeric metanephric kidneys using reverse transcription-polymerase chain reaction (RT-PC R). C himeric kidneys were formed by 1 ) separating the ureteric bud (U) from the metanephric mesenchyme $(M)$ of mouse $(m)$ at E11 and rat (r) at E13 days of gestation and 2) recombining the ureteric bud of one species with the metanephric mesenchyme of the other species (i.e., $U_{r} M_{m}$ and $\left.U_{m} M_{r}\right)$, follow ed by filter culture until differentiated. Species-specific restriction enzymes for all four genes were chosen to digest the PC R product from either rat or mouse. RT-PC R was performed for each mRN $A$ species and the products digested. The V2R product from the $U_{r} M_{m}$ chimera was cleaved by a restriction enzyme known to digest only ratproduct, suggesting the PCR product was produced predominantly by cells derived from the ureteric bud. The renin, $O \mathrm{TR}$, and THP products from both chimeras were cleaved equally well by species-specific restriction enzymes, suggesting the products were made by cells originating from both the ureteric bud and the metanephric mesenchyme. These studies demonstrate that the cultured chimeric meta nephric model is useful to study segment lineage. The results suggest that the lineage of at least certain portions of the nephron is heterogenous. Dev. G enet. 24:230-240, 1999. () 1999 W iley-Liss, Inc.
\end{abstract}

Key words: kidney; development; vasopressin receptor; Ta mm-Horsfall protein; renin; oxyto cin receptor

\section{INTRODUCTION}

The epithelial portions of the kidney are derived from two embryonic cell types, the metanephric mesenchyme and the ureteric bud. Based on early microdissection studies, it is generally accepted that the glomerulus, the proximal tubule, loop of Henle, and at least some parts of the distal tubule derive from the metanephric mesenchyme, while the collecting ducts originate from the ureteric bud. It is unclear exactly where the transition from mesenchyme to ureteric bud-derived structures occurs, or if there is a distinct transition. In 1905, Huber concluded that the ureteric bud produced only the collecting duct and that all other portions of the nephron were derived from the mesenchyme. Later studies supported this view [Oliver, 1968; Potter, 1972]. Howie et al. [1993] suggested a more proximal transition zone, such that the transition would occur between the end of the distal tubule and the beginning of the connecting tubule. Recent studies [Herzlinger et al., 1992; Qiao et al., 1995], however, suggest a more plastic system allowing intermixing of mesenchyme- and ureteric bud-derived cells throughout the nephron. Many different approaches may be necessary to fully understand the contributions of the mesenchyme and ureteric bud to the various portions of the nephron. One approach, as described here, is to exploit the phenotypic variations in the different segments of the nephron by using molecules that have a relatively well-localized pattern of expression.

In the mature and developing kidney, renin, TammHorsfall protein (THP), the oxytocin receptor (OTR), and the vasopressin type 2 receptor (V2R) have relatively restricted expression patterns which are well defined. Renin is very specifically expressed in the periglomerular arterioles and in the proximal tubule in the adult [Taugner et al., 1982]. In the embryonic kidney, renin is found in the arcuate and interlobar arteries, as well as in the afferent arterioles [Reddi et al., 1998]. The V2R is expressed in the collecting duct and thick ascending limb (TAL) in mature kidneys [Ostrowski et al., 1992] and is restricted to the collect-

Contract grant sponsor: NIH NRSA DK 09325; Contract grant sponsor: NIH; Contract grant numbers: DK37448, DK 39255, and DK 40042.

*Correspondence to: Lois J . Arend, Ph.D., M.D., Department of Pathology, 1150 W. Medical Center Drive, 1560 MSRB II, Ann Arbor, MI 48109-0676. E-mail: larend@umich.edu

Received 28 August 1998; Accepted 30 November 1998 
ing duct structures in the developing metanephros [Ostrowski et al., 1993]. In the adult, THP is expressed in the TAL of Henle's loop and in some cells of the early distal convoluted tubule [Sikri et al., 1981; Howie and J ohnson, 1992]. The same expression pattern is found in the embryonic kidney when these segments of the nephron begin developing [Howie et al ., 1993]. The OTR is restricted in expression in the mature kidney to the macula densa and a few cells of the distal convoluted tubule [Ostrowski et al., 1995]. This pattern of expression is the same in the embryonic kidney with additional expression in the devel oping TAL [Schmidt et al., 1990; Ostrowski et al., 1995].

With chimeric kidneys produced from the ureteric bud of one species and mesenchyme of another species, using reverse transcription-polymerase chain reaction (RT-PCR) and species-specific restriction enzymes, we were able to determine the species of origin and the embryonic progenitor of the cells expressing renin, OTR, THP, and V2R mRNA. The results indicate that the lineage of the cells expressing these molecules is not confined to a single embryonic cell type.

\section{MATERIALS AND METHODS Animals and Dissection}

Timed-pregnant mice and rats were obtained from Harlan Sprague Dawley (Indianapolis, IN) and sacrificed by cervical dislocation at 11.5 days of gestation for the mouse and 13.5 days for the rat (day zero of gestation designated as day of vaginal plug). A midline abdominal incision was made to expose the uterine horns which were removed asceptically and placed in cold culture medium (Dulbecco's modified Eagle's medium [DMEM] supplemented with $10 \%$ fetal calf serum, $2 \mathrm{mM}$ glutamine, $1 \mathrm{M}$ dexamethasone, and $50 \mathrm{~g} / \mathrm{ml}$ each penicillin and streptomycin). Embryos were removed from the placental membranes and placed in cold phosphate buffered saline (PBS; $8 \mathrm{mM}$ $\mathrm{NaH}_{2} \mathrm{PO}_{4} \cdot \mathrm{H}_{2} \mathrm{O}, 140 \mathrm{mM} \mathrm{NaCl}, 3 \mathrm{mM} \mathrm{KCl}, 1.5 \mathrm{mM}$ $\mathrm{KH}_{2} \mathrm{PO}_{4}, \mathrm{pH}$ 7.43) for dissection of the metanephroi. E mbryonic kidneys were cultured intact, or in chimeric form with the ureteric bud from one species and the mesenchyme from the other species, using a modification of the transfilter system developed by Grobstein [1956]. Kidneys were placed on filters (polycarbonate, Costar) sitting atop a metal screen with a central hole, in six-well culture plates. The volume of the culture medium was adjusted to wet thefilter without submerging the tissue. The kidneys were incubated at $37^{\circ} \mathrm{C}$ with $5 \% \mathrm{CO}_{2}$.

To develop cultured chimeric metanephric kidneys, the ureteric bud was removed from the metanephric mesenchyme by a 5-minute incubation of the intact kidney in $1 \mathrm{mM}$ EDTA in PBS containing $10 \mathrm{U}$ DNase/ $\mathrm{ml}$, followed by manual separation. Both portions were then incubated for 5 minutes in culture medium. The ureteric bud from one species was transferred to the culture apparatus, then the metanephric mesenchyme from the other species was transferred onto the filter and manually overlaid onto the ureteric bud. Chimeras were incubated under the same conditions described above. However, they were generally kept in culture 2-3 days longer than intact kidneys as they lagged slightly in branching of the ureteric bud and differentiation of the mesenchyme. Chimeras produced by combining the ureteric bud $(U)$ from the rat $(r)$ with the metanephric mesenchyme $(M)$ from the mouse $(m)$ are designated $U_{r} M_{m}$, while the opposite cross is designated $U_{m} M_{r}$.

\section{Confocal Microscopy}

To evaluate the progression of development of the chimeric metanephric kidneys in culture, they were compared to intact metanephric kidneys by confocal microscopy. Briefly, while attached to the filters, the kidneys were washed in PBS to remove the culture medium. They were fixed in $2 \%$ paraformaldehyde in PBS, pH 7.4, for 10 minutes at room temperature and stored in $0.5 \%$ paraformaldehyde in PBS at $4^{\circ} \mathrm{C}$ until use. The filters were washed twice in PBS and the kidneys permeabilized with $0.3 \%$ Triton X-100 in PBS for 5 minutes. The kidneys were incubated in propidium iodide $(0.1 \mathrm{mg} / \mathrm{ml}$ PBS) for 5 minutes at room temperature. The kidneys were then removed from the filters and mounted in Vectashield (Vector Labs) between two coverslips. I mages were obtained on a BioRad (Hercules, CA) MRC 600 laser scanning confocal microscope with a YHS filter set containing a 568 DF 10 excitor filter, a 585 DRLP dichroic reflector, and a 585 EFLP emission filter. Images were processed with Adobe Photoshop software.

\section{Determination of mRNA Expression by RT-PCR}

To determinemRNA expression in the cultured metanephric kidneys, intact or chimeric kidneys were cultured as described above for 6 to 8 days, removed from the filter, snap-frozen in guanidine isothiocyanate solution, and stored at $-80^{\circ} \mathrm{C}$ until use. Total RNA was then isolated using a discontinuous gradient of cesium chloride, with Escherichia coli ribosomal RNA as carrier. CDNA was synthesized by incubating RNA at $42^{\circ} \mathrm{C}$ for 1 hour with H-MMLV reverse transcriptase (Superscript; BRL, Gaithersburg, MD), oligo dT (Pharmacia, Piscataway, $\mathrm{NJ}$ ) as primer, RNAsin (Promega, Madison, WI), dithiothreitol, dNTPs (Pharmacia), and bovine serum albumin (BSA; Boehringer Mannheim, Indianapolis, IN). The CDNA was precipitated with linear acrylamide and resuspended in Tris-EDTA buffer.

For amplification, $\mathrm{PCR}$ reactions were performed in a total volume of $50 \mu \mathrm{l}$ in the presence of $0.1 \mathrm{mM}$ dNTP, 10 $\mathrm{mM}$ dithiothreitol, $50 \mathrm{mM} \mathrm{KCl}, 1.5 \mathrm{mM} \mathrm{MgCl} 2,10 \mathrm{mM}$ Tris (pH 8.3), and $0.001 \%$ gelatin, with $0.5 \mathrm{pmol}$ of each primer, $1.25 \mathrm{U}$ Taq DNA Polymerase (Perkin-Elmer Cetus, Norwalk, CT), $1.5 \mu \mathrm{Ci}$ 32P dCTP (Amersham, Arlington Heights, IL), and 1-6 $\mu$ of tissue CDNA. 
AREND ET AL.

TABLE 1. Sequence of Primer, Resulting Amplification Product Size, and Nucleotide Position for Each Molecule

\begin{tabular}{|c|c|c|c|c|}
\hline Molecule & & Primer sequence & Size (bp) & Position \\
\hline THP & $\begin{array}{l}\text { Sense } \\
\text { Antisense }\end{array}$ & $\begin{array}{l}\text { 5' CTG GAT GTC CAT AGT GAC TC 3' } \\
\text { 5' TGT GGC ATA GCA GTT GGT CA 3' }\end{array}$ & 399 & $1152-1551$ \\
\hline V2R & $\begin{array}{l}\text { Sense } \\
\text { Antisense }\end{array}$ & $\begin{array}{l}\text { 5' TTT CAA GTG CTA CCC CAG CT 3' } \\
\text { 5' AAT CGG GCC CAG CAA TCAAA 3' }\end{array}$ & 316 & $312-628$ \\
\hline Renin & $\begin{array}{l}\text { Sense } \\
\text { Antisense }\end{array}$ & $\begin{array}{l}\text { 5' TGG GTC CCC TCC ACC AAG T 3' } \\
\text { 5' TCC CAG GGC TTG CAT GAT CA 3' }\end{array}$ & 600 & 540-1139 \\
\hline OTR & Antisense & $\begin{array}{l}\text { 5' A GC GTT TGG GAC GTC AAT GCG 3' } \\
\text { 5' GGC TAT GGC TCA TGC TGA AGA TGG 3' }\end{array}$ & 288 & $111-369$ \\
\hline$\beta$-actin & $\begin{array}{l}\text { Sense } \\
\text { Antisense }\end{array}$ & $\begin{array}{l}\text { 5' AAC CGC GAG AAG ATG ACC CAG ATC ATG TTT 3' } \\
\text { 5' AGC AGC CGT GGC CAT CTC TTG CTC GAA GTC 3' }\end{array}$ & 350 & $384-734$ \\
\hline
\end{tabular}

Mineral oil was layered on top of each sample to prevent evaporation. After an initial denaturation at $94^{\circ} \mathrm{C}$ for 3.5 minutes, PCR amplification was performed for 30 cycles at $94^{\circ} \mathrm{C}$ (denaturation) for 1 minute, $54^{\circ} \mathrm{C}$ (annealing) for 1.5 minutes, and $72^{\circ} \mathrm{C}$ (extension) for 1 minute, followed by incubation at $72^{\circ} \mathrm{C}$ for 8 minutes. Primers were chosen from published sequences in an area of homology between the rat and mouse sequence to allow amplification of both species with the same primer pair. Sequences of all primers used and the expected sizes of amplification products are summarized in Table 1 [Yu et al., 1994; Lolait et al., 1992; Burnham et al., 1987; Rozen et al., 1995; Gunning et al., 1983]. B-actin was used as a housekeeping gene to control for variations in sample DNA. To ensure that similar amounts of cDNA template were present between the various samples, serial 10-fold dilutions of each sample were amplified with ß-actin primers. After quantitation of the radioactivity, the CDNA was diluted appropriately to provide CDNA equal to that in the sample with the lowest ß-actin mRNA abundance. Amplifications were then performed on the B-actin normalized CDNA. From each PCR reaction, the product contained in $45 \mu \mathrm{l}$ was precipitated with $5 \%$ linear acrylamide, $4 \mathrm{M}$ ammonium acetate, and 100\% ethanol, resuspended in TE buffer ( $\mathrm{pH} 8.0)$, and run on a $5 \%$ polyacrylamide gel. ${ }^{32} \mathrm{P}$ incorporation into bands was detected by autoradiography and quantitated using Phosphor Analyst software on a GS-250 Molecular I mager system (Bio-Rad).

\section{Cloning and Sequencing of the Mouse THP and V2R PCR Products}

To distinguish between the PCR products made by the mouse and rat, the nucleotide sequence of both species was needed. The rat sequence was available from the literature for both THP and V2R. The sequence of the mouse PCR product was determined by TA cloning and sequencing of the PCR product. Briefly, the PCR products were ligated into the $\mathrm{PCR}$ vector (I nvitrogen Corp., San Diego, CA) and competent bacteria were transformed with the plasmid. Positive colonies were picked and grown in LB media containing ampicillin. Mini-prep DNA (Qiagen, Chatsworth, CA) from overnight cultures of the clones was subjected to restriction digestion with EcoRI to verify the presence of an appropriate sized insert. Plasmid DNA was sequenced on an $\mathrm{ABI} 373 \mathrm{~A}$ autosequencer. Sequences were compared to known sequences of other species by the Blast program of the National Center for Biotechnology I nformation.

\section{Restriction Enzyme Digestion of PCR Products}

PCR products were precipitated as described above and resuspended in $\mathrm{dH}_{2} \mathrm{O}$. Five microliters of product was incubated at $37^{\circ} \mathrm{C}$ in a total volume of $10 \mu \mathrm{l}$ containing restriction enzyme, 10X restriction buffer, and BSA. Restriction enzymes that could produce digestion of either rat or mouse product, but not both species, were chosen based on computer-generated restriction maps of the PCR product sequences. Restriction digestion was initially performed on the PCR product from mouse and rat intact cultured metanephric kidneys to confirm digestion of only one of the products. Enzymes which were proven to differentiate between the species were then used to digest PCR product from chimeric kidneys, to determine the spedies of origin of the product. Restriction fragments of chimeric product were analyzed by densitometry to determine the percentage of product in the fragments relative to the total product.

\section{RESULTS \\ Development of Chimeric Metanephric Kidneys}

Figure 1 shows a representative chimeric metanephric kidney after 7 days in culture. While the chimeric kidneys are somewhat disordered and lack the stereotyped, repetitive devel opment seen in intact explants, they do develop well-defined comma- and S-shaped bodies and there is extensive branching of the ureteric bud. Metanephric mesenchyme prepared in the same manner, but cultured without a ureteric bud, underwent apoptosis within 2-3 days of explantation (results not shown). Likewise, ureteric bud dissected free of mesenchyme, identical to that obtained for chimeric cultures, failed to branch or produce tubular structures or nascent glomeruli when cultured alone (results not shown). As shown previously [Gruenwald, 1943; Sariola 

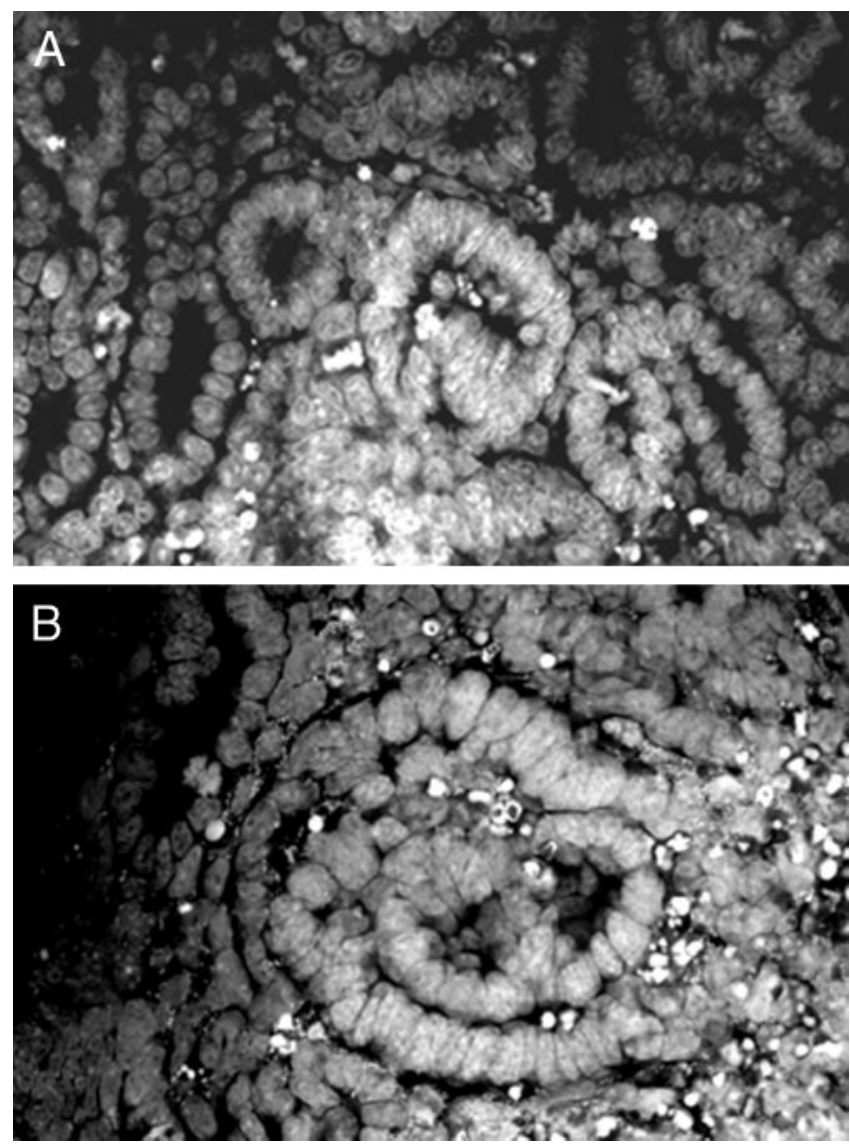

Fig. 1. Confocal microscopic images of a chimeric metanephric kidney composed of ureteric bud from an 11.5 day gestation mouse and metanephric mesenchyme from a 13.5 day gestation rat $\left(U_{m} M_{r}\right)$ after 7 days in culture. A: Comma-shaped body and developing tubules. B: S-shaped body. Nuclei are visualized with propidium iodide.

et al., 1989], isolated metanephric mesenchyme, when cultured with spinal cord tissue, also devel oped nascent glomerular structures.

\section{Restriction Digestion of Renin PCR Product}

The restriction enzymes EcoRI and BstXI were chosen to differentiate between mouse and rat renin PCR products based on the restriction maps for each species. The results of digestion of renin PCR product from either mouse or rat intact cultured metanephric kidneys are shown in Figure 2.

As expected, E coRI cut the rat product (600 bp uncut) into two fragments of 100 and $500 \mathrm{bp}$, but did not digest the mouse product. BstXI cut the mouse renin product into 85 and 515 bp fragments but failed to cut the rat renin product.

\section{Origin of Renin PCR Product F rom Chimeric Metanephric Kidneys}

Renin PCR product from chimeric kidneys was subjected to restriction digestion with EcoRI and BstXI.
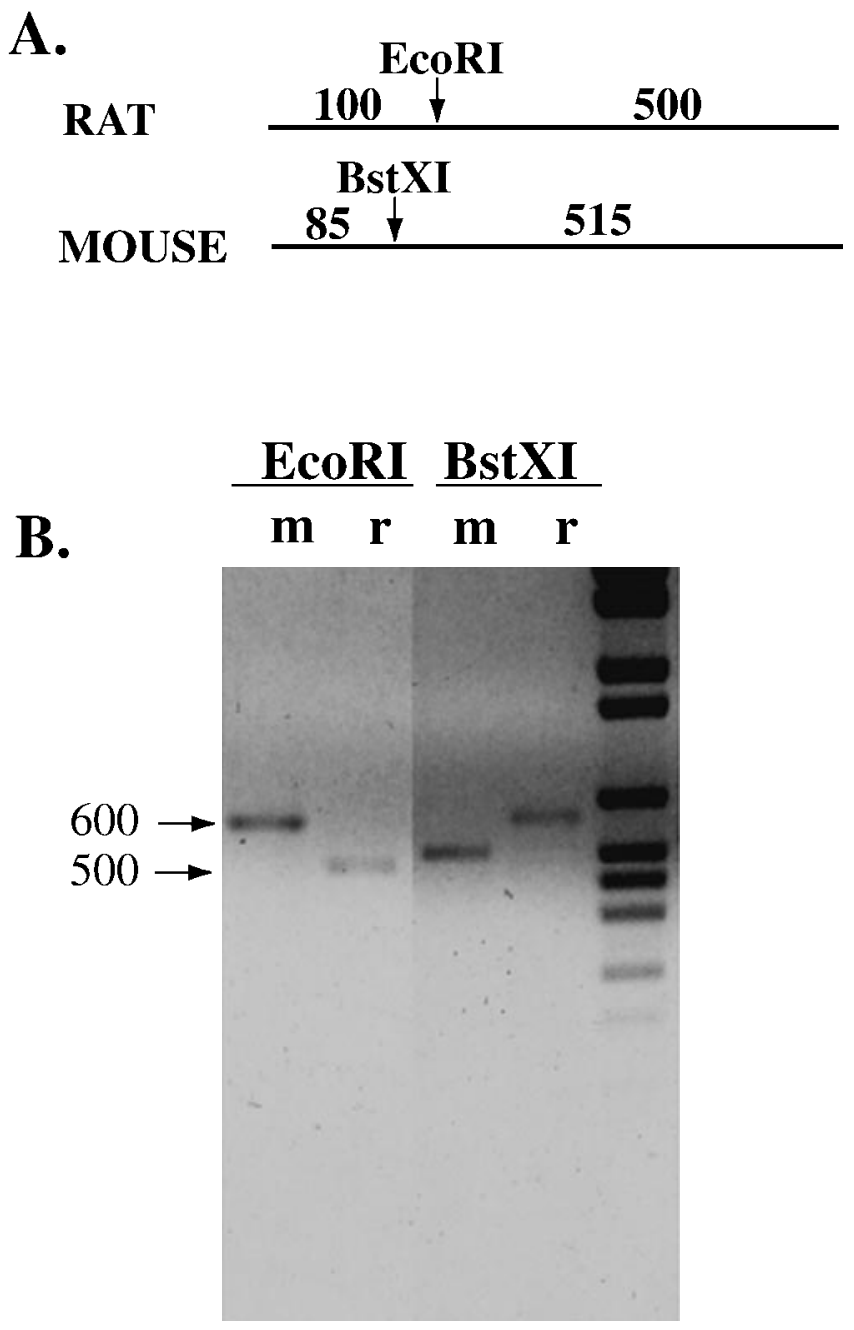

Fig. 2. Restriction digestion of renin $P C R$ product from intact mouse and rat cultured metanephric kidneys. A: Expected digestion pattern of mouse and rat renin product by E CORI and BstXI based on restriction maps for each species. Undigested product is $600 \mathrm{bp}$. E coRI is expected to cleave only rat renin PCR product into 100 and $500 \mathrm{bp}$ fragments, while BstXI should cut mouse product into 85 and $515 \mathrm{bp}$ fragments. B: Renin PCR product from intact mouse and rat cultured metanephric kidneys digested with EcoRI and BstXI. The rat product is cut by E coRI and the mouse product is cut by BstXI as expected from the restriction maps.

The PCR product from both chimeras (Fig. 3) was digested equally well by both enzymes. By densitometry, $53.9 \pm 3.8 \%$ of the renin product from $U_{r} M_{m}$ chimeras $(n=8)$ was found in the restriction fragments when EcoRI was used and $54.1 \pm 5.1 \%$ was digested when BstXI was used. Similar results were found with the $U_{m} M_{r}$ chimeras $(n=4)$. When EcoRI was used to digest the $U_{m} M_{r}$ chimeras, $52.7 \pm 6.5 \%$ of the product was found in the fragments, while BstXI digestion of the renin product from $U_{m} M_{r}$ chimeras resulted in $55.9 \pm 1.8 \%$ of the product in fragments. These results indicate that the renin mRNA present was produced by 


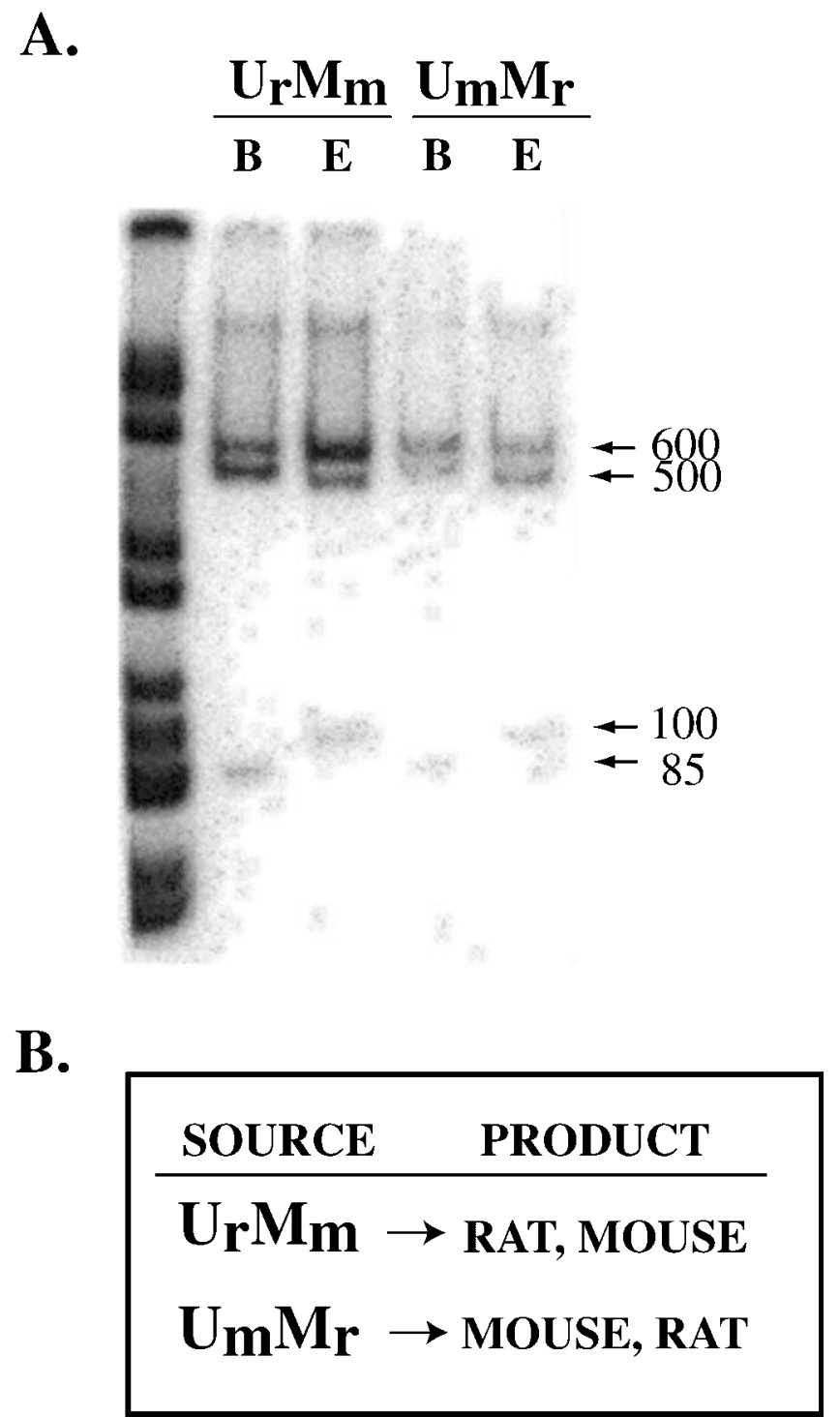

Fig. 3. Restriction digestion of chimeric metanephric kidney renin PCR product. A: Autoradiogram of ${ }^{32} \mathrm{P}$-labeled renin PCR product from representative $U_{r} M_{m}$ and $U_{m} M_{r}$ chimeras after digestion with $E c o R I$ and BstXI. Undigested product is $600 \mathrm{bp}$. Approximately $55 \%$ of the renin product from either type of chimera was found in the fragments when either BstXI (B) or EcoRI (E) was used. B: In either chimeric metanephric kidney type, both mouse and rat contributed to the renin product, suggesting the cellular derivation was both metanephric mesenchyme and ureteric bud.

cells originating from both species. Therefore, these cells derived from both the metanephric mesenchyme and ureteric bud.

\section{Restriction Digestion of OTR PCR Product}

The restriction enzymes Banl and Ncil were chosen to differentiate between mouse and rat OTR PCR products based on the restriction maps for each species (Fig. 4A). The results of digestion of OTR PCR product

\begin{tabular}{lll} 
A. & \multicolumn{1}{c}{ Nci I } & 177 \\
\cline { 2 - 3 } MOUSE & Ban I & \\
\cline { 2 - 2 } &
\end{tabular}

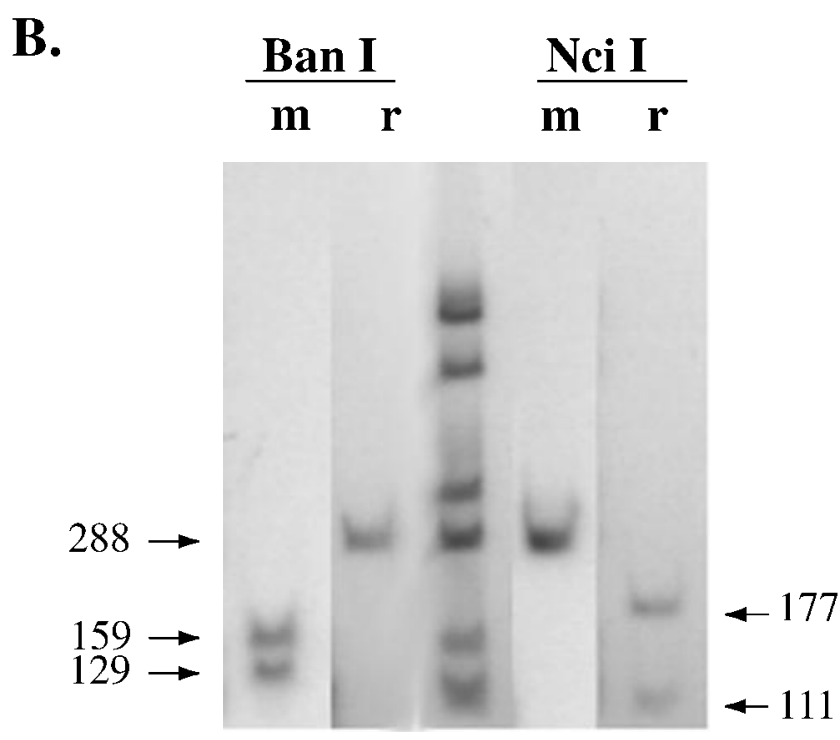

Fig. 4. Restriction digestion of OTR PCR product from intact mouse and rat cultured metanephric kidneys. A: Expected digestion pattern of mouse and rat OTR product by $\mathrm{Banl}$ and $\mathrm{Ncil}$ based on restriction maps for each species. Undigested product size is $288 \mathrm{bp}$. Banl would be expected to cleave only mouse OTR PCR product into 129 and 159 bp fragments, while Ncil should cut only the rat product (111 and 177 bp fragments). B: OTR PCR product from intact mouse and rat cultured metanephric kidneys digested with Banl and Ncil. The mouse product is cut by Banl and the rat product is cut by $\mathrm{Ncil}$ as expected from the restriction maps.

from either mouse or rat intact cultured metanephric kidneys are shown in Figure 4.

As expected, Banl cut the mouse product (288 bp uncut) into two fragments of 129 and 159 bp (Fig. 4B), but did not digest the rat product. N cil cut the rat OTR product into 111 and 177 bp fragments but failed to cut the mouse OTR product.

\section{Origin of OTR PCR Product From Chimeric Metanephric Kidneys}

OTR PCR product from chimeric cultured kidneys was subjected to restriction digestion with Banl and Ncil. The PCR product from both chimeras (Fig. 5A) was digested equally well by both enzymes. By densitometry, $60.6 \pm 3.6 \%$ of the OTR product from $U_{r} M_{m}$ 

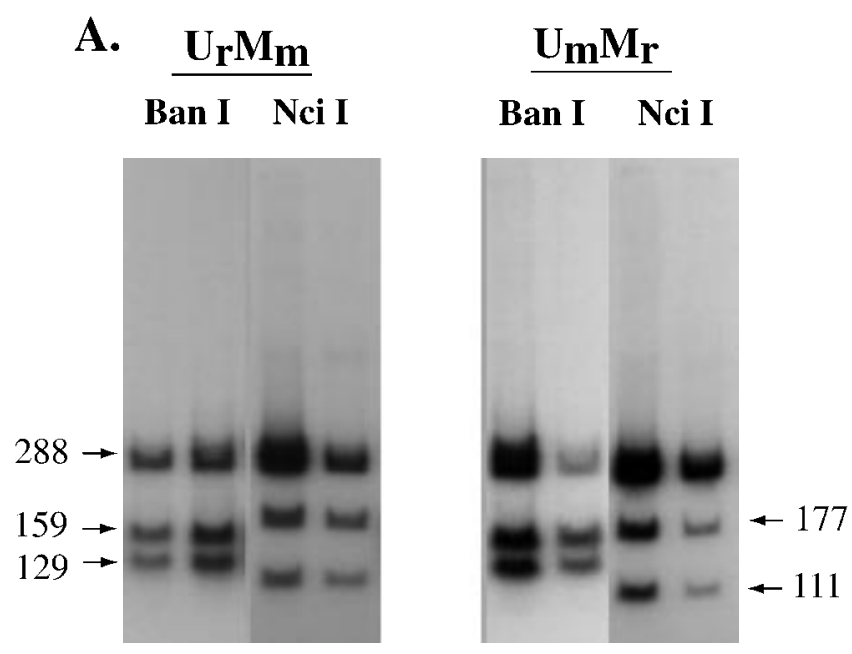

B.

\begin{tabular}{l} 
SOURCE $\quad$ PRODUCT \\
\hline UrMm $_{\mathbf{r}} \rightarrow$ RAT, MOUSE \\
UmMr $_{\mathbf{m}} \rightarrow$ MOUSE, RAT
\end{tabular}

Fig. 5. Restriction digestion of chimeric metanephric kidney OTR PCR product. A: OTR PCR product from representative $U_{r} M_{m}$ and $\mathrm{U}_{\mathrm{m}} \mathrm{M}_{\mathrm{r}}$ chimeras after digestion with Banl and $\mathrm{Ncil}$. Undigested product is $288 \mathrm{bp}$. Approximately $55-60 \%$ (see Results) of the OTR product from either type of chimera was found in the fragments when either Banl or Ncil was used. B: In either chimeric metanephric kidney type, both the mouse ard rat contributed to the OTR product, suggesting the cellular derivation was both metanephric mesenchyme and ureteric bud.

chimeras ( $n=13$ ) was found in the restriction fragments when Banl was used and $55.9 \pm 3.7 \%$ was digested when $\mathrm{N}$ cil was used. Similar results were found with the $U_{m} M_{r}$ chimeras $(n=16)$. When Banl was used to digest the $U_{m} M_{r}$ chimeras, $62.9 \pm 1.9 \%$ of the product was found in the fragments, whereas $\mathrm{Ncil}$ digestion of the OTR product from $U_{m} M_{r}$ chimeras resulted in $58.6 \pm 2.3 \%$ of the product in the fragments.

\section{Sequence of Mouse V2R Receptor PCR Product}

The mouse homologue of the PCR product for V2R was cloned and the sequence is shown in Figure 6 compared to the published sequence for rat [Lolait et al., 1992]. The mouse sequence is $97 \%$ identical to the rat at the nucleotide level in this area of the molecule. This sequence was used to generate a restriction enzyme map for the mouse V2R PCR product to identify species-specific restriction enzymes.

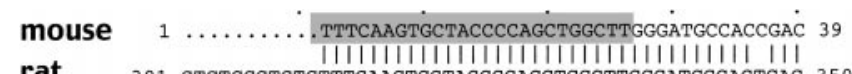

rat 301 CTGTGGCTCTGTTTCAAGTGCTACCCCAGCTGGCTTGGGATGCACTGAC 350

40 CGCTTCCATGGCCCTGACGCCTTGTGTCGGGCCGTCAAGTACCTGCAGAT 89 |||||||||||||||||||||||||||||||||||||||||||||||| 351 CGCTTCCATGGCCCTGATGCCCTGTGTCGGGCCGTCAAGTACCTGCAGAT 400

90 GGTGGGCATGTATGCCTCTTCCTACATGATCCTGGCCATGACACTAGACC 139 |||||||||||||||||||||||||||||||||||||||||||||| $\mid$ 401 GGTGGGCATGTATGCCTCCTCCTACATGATCCTGGCCATGACACTAGACC 450

140 GCCATCGCGCCATCTGCCGCCCTATGCTGGCATACCGCCATGGAGGTGGG 189 |l||\|ा| $|\|\|\|\|\|\|\|\|\|\|\|\|\||\|\|\|\|\|\|\|\|\|\|\|\|\|\||$ 451 GCCATCGTGCCATCTGCCGCCCTATGCTAGCATACCGCCATGGAGGTGG 500

190 GCTCGCTGGAACAGGCCAGTGCTGGTGGCCTGGGCCTTCTCACTCCTTCT 238 1111111111111111111111111111111111111111111111111 501 GCTCGCTGGAACAGGCCAGTGCTGGTGGCCTGGGCCTTCTCACTCCTTCT 550

239 CAGCCTGCCTCAGCTCTTCÄTCTTTGCTCACGGTGATGTGGGAAATGGCA 289

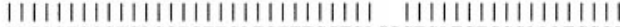
551 CAGCCTGCCTCAGCTCTTCATCTTTGCTCAGCGTGATGTGGGAAATGGCA 600 290 GTGGGGTATTTGATTGCTGGGCCCGAT,

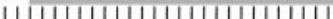

601 GTGGGGTGTTTTGATTGCTGGGCCCGATTTTGCAGAACCATGGGGCCTTCGT 650

Fig. 6. Sequence of mouse V2R PCR product (upper row) aligned with known rat sequence (lower row). Shaded areas represent regions used as forward and reverse PCR primers. Total amplification product size: $316 \mathrm{bp}$. Vertical bars indicate nucleotide identity between species (97\%).

\section{Restriction Digestion of the V2R PCR Product}

The restriction enzyme $\mathrm{Nhel}$ was chosen to differentiate between mouse and rat V2R PCR products based on the restriction maps for each species (Fig. 7A). Results of Nhel digestion of the V2R product from intact mouse and rat cultured metanephric kidneys are shown in Figure 7B. Nhel cleaved the rat V2R product into 166 and 150 bp fragments, but as expected, did not cut the mouse product (undigested product size: $316 \mathrm{bp}$ ).

\section{Origin of V2R PCR Product From Chimeric Metanephric Kidneys}

V2R PCR product from chimeric cultured kidneys was subjected to restriction digestion with $\mathrm{Nhel}$. The PCR product from chimeras of the $U_{r} M_{m}$ type (Fig. 8, left panel; $n=7$ ) was digested by Nhel to produce fragments of the expected size. The band at approximately 600 bp represents a doublet of the 316 bp V2R PCR product. By densitometry, $77.3 \pm 7.6 \%$ of the V2R product from $U_{r} M_{m}$ chimeras was found in the restriction fragments. These results are consistent with product derived predominantly from the rat portion of the $U_{r} M_{m}$ chimera, i.e., the ureteric bud. Alternatively, $33.4 \pm 7.8 \%$ of the $V 2 R$ product from $U_{m} M_{r}$ chimeras (Fig. 8, right panel; $n=9$ ) was found in the restriction fragments, leaving nearly $70 \%$ uncut, consistent with the PCR product derived predominantly from themouse portion in this chimera, i.e., the ureteric bud. Differential restriction enzyme digestion of these two chimeras by Nhel consistently demonstrated that the V2R mRNA present in these chimeras predominantly derived from the ureteric bud, rather than from the metanephric mesenchyme. 
A.

RAT 150 Nhe I

$\begin{array}{r}\text { Nhe I } \\ 150 \quad 166 \\ \hline 316 \\ \hline\end{array}$

B.

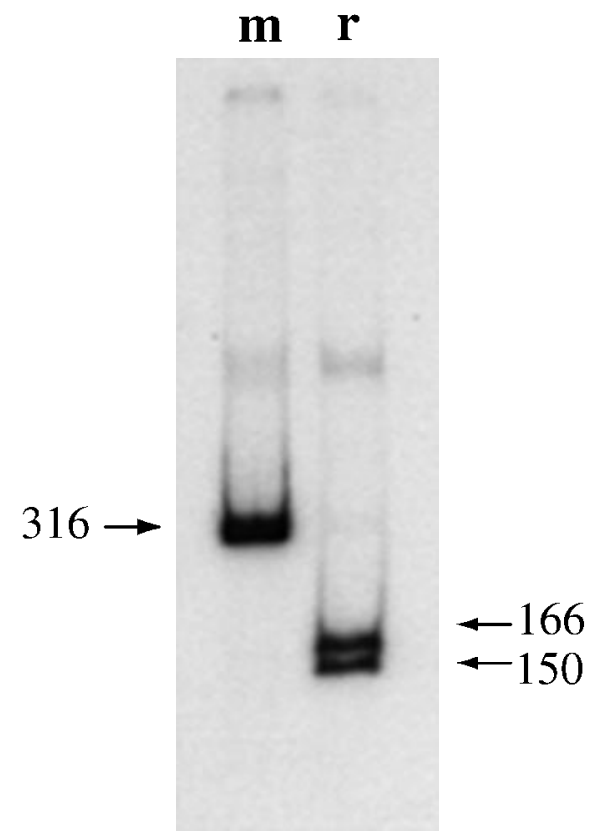

Fig. 7. Restriction digest of $V 2 R$ PCR product from mouse and rat cultured metanephric kidneys. A: Expected digestion pattern of mouse and rat V2R product by Nhel based on restriction maps of the PCR product from each species. Undigested product is $316 \mathrm{bp}$. Nhel should cleaverat to produce 166 and 150 bp fragments. Nhel should not digest mouse V2R product. B: Autoradiogram of mouse and rat V2R PCR products digested with $\mathrm{Nhel}$, producing the expected restriction fragment pattern; only the rat product is cleaved by Nhel .

\section{Sequence of Mouse THP PCR Product}

The mouse homologue of the PCR product for THP was cloned and the sequence is shown in Figure 9 compared to the published sequence for rat [Yu et al., 1994]. The mouse sequence is $92 \%$ identical to the rat at the nucleotide level in this area of the molecule. A restriction enzyme map of this mouse sequence for the THP PCR product was generated to identify speciesspecific enzymes.

\section{Restriction Digestion of THP PCR Product}

The restriction enzyme Banll was chosen to differentiate between mouse and rat THP PCR product
A.

\section{$\mathbf{U}_{\mathbf{r}} \mathbf{M}_{\mathbf{m}} \quad \mathbf{U}_{\mathbf{m}} \mathbf{M}_{\mathbf{r}}$}

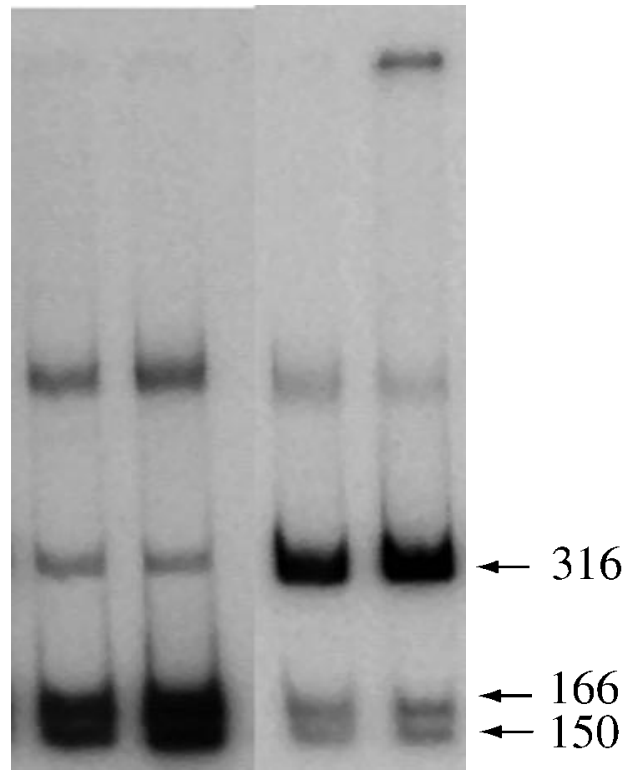

B.

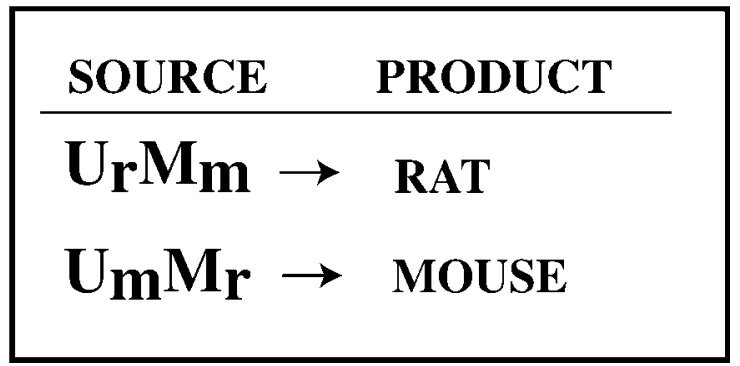

Fig. 8. Restriction digest of chimeric metanephric kidney V2R PCR products. A: Autoradiogram of ${ }^{32} \mathrm{P}$-labeled V2R PCR product from $U_{r} M_{m}$ and $U_{m} M_{r}$ chimeras after digestion with Nhel. Undigested product is $316 \mathrm{bp}$. The V2R PCR product from the $\mathrm{U}_{\mathrm{r}} \mathrm{M}_{\mathrm{m}}$ chimera is digested by $\mathrm{Nhel}(77.3 \pm 7.6 \%$ of total product in fragments, $n=7)$ but the product from the $U_{m} M_{r}$ chimera was not cut (33.4 $\pm 7.8 \%$ of total product in fragments, $\mathrm{n}=9$ ). B: The species producing the $\mathrm{V} 2 \mathrm{R}$ product in the $U_{r} M_{m}$ chimera, based on the restriction digest pattern, is rat. In the $U_{m} M_{r}$ chimera, mouse tissue produced the $V 2 R$. In each case, the V2R was produced by the species that provided the ureteric bud.

(Fig. 10A). Results of Banll digestion of the THP product from intact mouse and rat cultured metanephric kidneys are shown in Figure 10B. Banll cleaved the THP product from the mouse into 270 and $130 \mathrm{bp}$ fragments, but as expected, did not cut rat product (400 bp). 


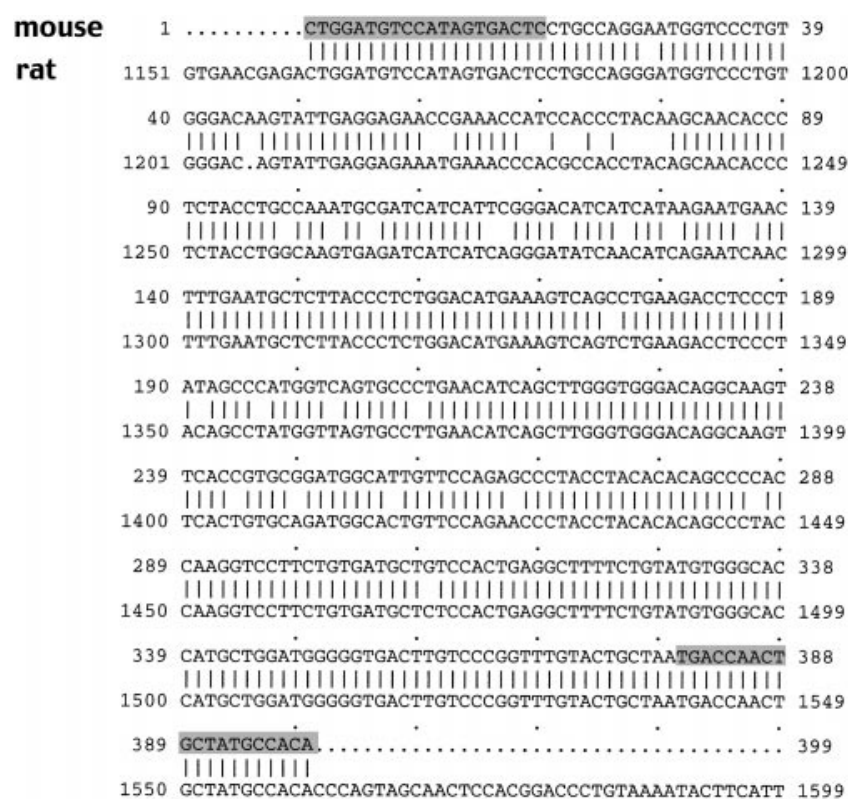

Fig. 9. Sequence of mouse THP PCR product (upper row), aligned with known rat sequence (lower row). Shaded areas represent regions used as forward and reverse PCR primers. Total amplification product size: 400 bp. Vertical bars indicate nucleotide identity between species $(92 \%)$

\section{Origin of THP PCR Product From Chimeric Metanephric Kidneys}

THP PCR product from cultured chimeric kidneys was subjected to restriction digestion with Banll. THP product from chimeras of both types (Fig. 11A) was digested by Banl I to a similar degree. By densitometry, $61 \pm 3.4 \%$ of the THP product from $U_{r} M_{m}$ chimeras $(n=$ 16) was found in the restriction fragments and $70.9 \pm$ $2.2 \%$ of the THP product from $U_{m} M_{r}$ chimeras $(n=14)$ was cut by Banl I. Since Banl I is capable of cutting only the mouse THP product, and just over one half of the PCR product is found in the restriction fragments in both chimeras, these results are consistent with THP product derived from both the metanephric mesenchyme and the ureteric bud.

\section{DISCUSSION}

The phenotypic variation of the nephron is striking; there are at least 16 different types of epithelium from the glomerulus to the collecting duct. The distinctions are evident at the ultrastructural level as well as at the functional level, with wide-ranging differences in transport capabilities and hormone responsiveness. All of these diverse cellular phenotypes evolve from two simple embryologic cell types, undifferentiated metanephric mesenchyme, and an epithelial outgrowth of the Wolffian duct, the ureteric bud. Classically, the nephron has been vi ewed as two distinct groups of cells,
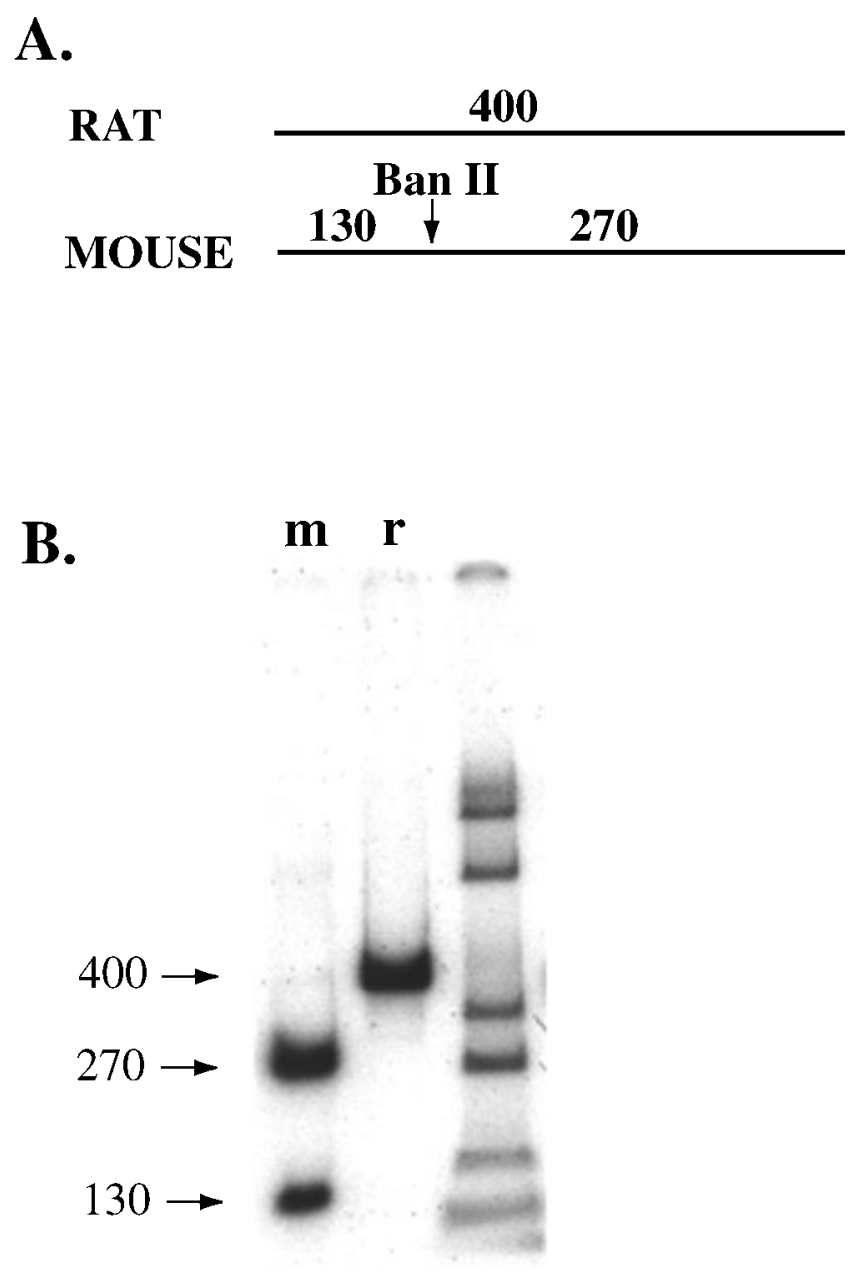

Fig. 10. Restriction digest of THP PCR product from mouse and rat metanephric kidneys. A: Expected digestion pattern of mouse and rat THP product by Banll. Undigested product is $400 \mathrm{bp}$. Banll should cleave mouse THP to produce 270 and 130 bp fragments but should not digest the rat THP product based on restriction maps of the PCR product from each species. B: Autoradiogram of mouse and rat THP PCR products digested with Banl I, producing the expected restriction fragment pattern; only the mouse product is cleaved by Banl I.

i.e., those that derive from undifferentiated mesenchyme and those that derive from ureteric bud cells. Controversy remains regarding the point in the nephron where mesenchyme-derived cells end and ureteric bud-derived cells begin. Indeed, there is recent evidence to suggest that this "segmentation" is somewhat artificial and cells derived from either embryonic precursor may be located at any point along the nephron [Herzlinger et al., 1992; Qiao et al., 1995]. Classically, it has been accepted that the collecting system per se is derived from the ureteric bud, while the remaining nephron is derived from differentiation of the metanephric mesenchyme into epithelial cells. With minor differences in the exact location of the transition from mesenchyme to ureteric bud-derived epithelium, Ol- 
A.

\section{$\underline{\mathrm{U}_{\mathbf{r}} \mathbf{M}_{\mathbf{m}}} \underline{\mathrm{U}_{\mathbf{m}} \mathbf{M}_{\mathbf{r}}}$}

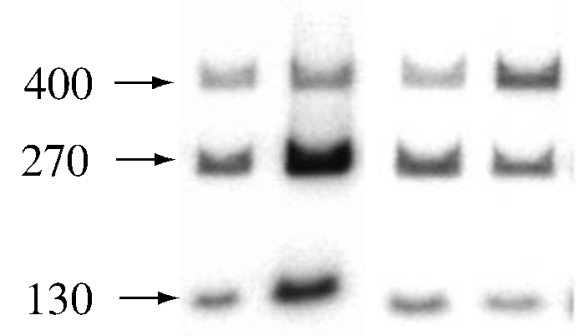

B.

\section{SOURCE PRODUCT \\ $\mathrm{U} \mathbf{r M m} \rightarrow$ RAT, MOUSE \\ $\mathrm{U}_{\mathbf{m}} \mathrm{Mr}_{\mathbf{r}} \rightarrow$ MOUSE, RAT}

Fig. 11. Restriction digest of chimeric metanephric kidney THP PCR product. A: Polyacrylamide gel of ${ }^{32}$ P-labeled THP PCR product from $U_{r} M_{m}$ and $U_{m} M_{r}$ chimeras after digestion with Banl I. U ndigested product is $400 \mathrm{bp}$. The THP products from both of the chimera types, $U_{r} M_{m}(61.0 \pm 3.4 \%$ of total product in fragments, $n=16)$ and $U_{m} M_{r}$ $(70.9 \pm 2.2 \%$ of total product in fragments, $n=14)$, are digested by Banl I. B: Based on the restriction digestion pattern of the chimeras, the THP product was produced by both species, and therefore, must have come from both ureteric bud- and mesenchyme-derived cells.

iver [1968], Potter [1972], and Howie et al. [1993] have all placed this region within the distal nephron, somewhere between the beginning of the distal convoluted tubule (DCT) and the beginning of the collecting duct. By using LacZ-tagged retroviruses, others have provided support for the hypothesis that a distinct transition point in fact does not exist and there is a mixture of mesenchyme and ureteric bud-derived cells throughout the nephron [Herzlinger et al., 1992; Qiao et al., 1995].

The phenotypic variation of the nephron provides an inherent means for exploring the question of cell lineage of the nephron. Genes that are highly localized within a specific portion of the nephron can be exploited as markers to determine the embryonic cell of origin of that portion of the nephron. We used RT-PCR of four relatively well-characterized molecules to investigate the cell of origin of segments of the nephron that express these molecules. The cell of origin of renin, THP, OTR, and V2R was determined in cultured ratmouse chimeric metanephric kidneys.

Cross-species chimeric metanephric kidneys formed by combining the ureteric bud from either the rat or mouse with the metanephric mesenchyme of the other species differentiated in culture to form developing nephrons similar to those of intact cultured metanephric kidneys. They were slower to begin differentiating, however, taking approximately 1-2 days before branching of the ureteric bud began and 3- 4 days before comma- or S-shaped bodies were well developed. The chimeric kidneys were rather unorganized, lacking the stereotypical repetitive morphology of the intact explants and there were fewer glomerular structures per kidney than in intact explants. However, by confocal microscopy, thes-shaped bodies that formed were nearly indistinguishable from those formed by intact metanephric kidneys. The comma- and s-shaped bodies in the chimeric kidneys were also similar in morphology to those produced when the metanephric mesenchyme was cultured in the presence of the spinal cord.

Preparations of the metanephric mesenchyme alone or the ureteric bud al one failed to differentiate as in the chimeras, even when up to five preparations of each were cultured together. These data suggest that any residual metanephric mesenchyme cells attached to the ureteric bud, or residual ureteric bud cells remaining within the mesenchyme, were not appreciable and would not be capable of differentiating into nephron structures in the chimeras. Therefore, in the case of THP, OTR, and renin, where the mRNA for each was derived from both ureteric bud and mesenchyme cell progenitors, contaminating residual cells from one or the other component could not be responsible for elaborating these genes.

The pattern of V2R mRNA expression has been demonstrated in embryonic, postnatal, and adult rats [Ostrowski et al., 1992, 1993]. It is localized in the mature kidney to cortical and medullary collecting ducts with some expression in the TAL. During gestation (embryonic days 16 and 19), V2R is expressed only in developing collecting duct structures. In the present study, V2R mRNA was elaborated predominantly from cells that derived from the ureteric bud, in keeping with its highly restricted expression pattern. The small proportion of mRNA that appears to have derived from the metanephric mesenchyme $(<20 \%)$ may be a result of minimal TAL development in the metanephric kidneys. Generally, in culture, metanephric kidneys do not devel op a significant loop of Henle and this may explain the relative lack of mesenchyme-derived expression of V2R. 
In adult human kidneys, THP is localized to the TAL of the loop of Henle and the early portion of the DCT and is absent from late distal tubule, connecting tubule, and collecting duct [Sikri et al., 1981; Howie and J ohnson, 1992]. In the embryonic kidney, the expression of THP parallels the development of the TAL and the early distal tubule [Howie et al., 1993]. In the present study, expression of THP was found to be from both ureteric bud- and mesenchyme-derived cel Is. These results imply that there is admixing of ureteric bud and metanephric mesenchyme cells along the midportion of the nephron, including at least the late TAL and early DCT. This region of the nephron is at the center of the area pinpointed as a possible transition zone.

In mature kidneys, renin is most highly expressed in the afferent arterioles but components of the reninangiotensin system, including renin mRNA, are also known to be present in the proximal tubule [Taugner et al., 1982]. Renin is expressed in the vascular tree to the level of the arcuate arteries when the vasculature is at an early stage of development. As the kidney matures, the expression of renin becomes more localized to the afferent arterioles [Reddi et al., 1998]. Renin mRNA has been detected in isolated intact metanephric kidneys at 11.5 days of gestation in the mouse (Arend, unpublished results), a time at which there is no appreciable vascular development. This suggests that renin is expressed at the earliest stages of kidney development in the metanephric mesenchyme, ureteric bud, or both, possibly in vascular progenitors that reside in one of these components. While the embryonic derivation of the vasculature is controversial, some vascular elements likely originate from the metanephric mesenchyme as well as from an extrametanephric source. The results from the cross-species chimeras in the present study demonstrate that, despite the known proximal expression pattern of renin mRNA, some ureteric budderived cells were responsible for renin production.

The OTR is expressed in the developing rat kidney by 17 days of gestation in both medullary and cortical regions [Schmidt et al ., 1990; Ostrowski et al ., 1995]. In the cortex, OTR was found in tubules near glomeruli, suggesting macula densa expression. Expression was also identified in distal tubules at PND4. In the medulla, OTR expression was transiently found in the papilla/inner medulla from E 17 to PND10, and later, from PND20 to PND30, during the period of weaning, only in the outer medulla. The structures expressing OTR in the medulla were felt to be loop of Henle, as collecting ducts were easily identifiable and not label ed. In mature kidneys, the OTR is exclusively in the cortex, primarily in the macula densa but with some expression in the DCT [Ostrowski et al., 1995]. In the present study, OTR mRNA expression was detected in cells that were derived from both ureteric bud- and metanephric mesenchyme-derived cells, supporting the hypothesis that there is a mixing of mesenchyme and ureteric bud cells al ong the nephron.
In summary, renin, THP, and OTR mRNA expression in cross-species chimeric metanephric kidneys is by cells whose progenitors were both ureteric bud and metanephric mesenchyme cells. Only V2R, which is local ized to the extreme distal nephron, showed almost exclusively ureteric bud-derived expression. These results, taken together with several studies suggesting no clear transition between mesenchyme and ureteric bud-derived cells in the nephron, indicate that the origin of each segment of the nephron may be more plastic than previously envisioned. It remains to be determined at which point in differentiation a cell is destined to become a member of a phenotypically distinct segment of the nephron.

\section{ACKNOWLEDGMENTS}

This research was supported in part by NIH NRSA DK09325 (L.J.A.) and by NIH grants DK37448, DK 39255, and DK 40042 (J.B.).

\section{REFERENCES}

Burnham CE, Hawelu-J ohnson CL, Frank BM, Lynch KR. 1987. Molecular cloning of rat renin CDNA and its gene. Proc Natl Acad Sci USA 84:5605-5609.

Grobstein C. 1956. Some transmission characteristics of the tubuleinducing influence on mouse metanephrogenic mesenchyme. Exp Cell Res 10:424-440.

Gruenwald P. 1943. Stimulation of nephrogenic tissue by normal and abnormal inductors. Anat Rec 86:321-339.

Gunning P, Ponte P, Okayama H, Engel J, Blau H, Kedes L. 1983. I solation and characterization of full-length CDNA clones for human alpha-, beta-, and gamma-actin mRNAs: Skeletal but not cytoplasmic actins have an amino-terminal cysteine that is subsequently removed. Mol Cell Biol 3:787-795.

Herzlinger D, Koseki C, Mikawa T, Al-Awqati Q. 1992. Metanephric mesenchyme contains multipotent stem cells whose fate is re stricted after induction. Development 114:565-572.

HowieAJ , J ohnson GD. 1992. Confocal microscopic and other observations on the distal end of the thick limb of the human loop of Henle. Cell Tissue Res 267:11-16.

Howie AJ , Smithson N, Rollason TP. 1993. Reconsideration of the development of the distal tubule of the human kidney. J Anat 183:141-147.

Huber C. 1905. On the development and shape of uriniferous tubules of certain higher mammals. AmJ Anat (Suppl) 4:1-98.

Lolait SJ , O'Carroll AM, McBride OW, Konig M, Morel A, Brownstein MJ . 1992. Cloning and characterization of a vasopressin V2 receptor and possiblelink to nephrogenic diabetes insipidus. Nature 357:336339.

Oliver J . 1968. Nephrons and kidneys. A quantititive study of developmental and evolutionary mammalian renal architectonics. New York: Harper \& Row.

Ostrowski NL, Lolait SJ , Bradley DJ , O'Carroll A-M, Brownstein MJ , Young WS. 1992. Distribution of V1a and V2 vasopressin receptor messenger ribonucleic acids in rat liver, kidney, pituitary, and brain. Endocrinology 131:533-535.

Ostrowski NL, Young WS, Knepper MA, Lolait SJ . 1993. Expression of vasopressin $\mathrm{V} 1 \mathrm{a}$ and $\mathrm{V} 2$ receptor messenger ribonucleic acid in the liver and kidney of embryonic, developing, and adult rats. Endocrinology 133:1849-1859.

Ostrowski NL, Young WS, Lolait SJ . 1995. Estrogen increases renal oxytocin receptor gene expression. Endocrinology 136:1804-1808.

Potter EL. 1972. Normal and abnormal development of the kidney. Chicago: Year Book Medical Publishers. 


\section{AREND ET AL.}

Qiao J, Cohen D, Herzlinger D. 1995. The metanephric blastema differentiates into collecting system and nephron epithelia in vitro. Development 121:3207-3214.

Reddi V, Zaglul A, Pentz ES, Gomez RA. 1998. Renin-expressing cells are associated with branching of the developing kidney vasculature. J Am Soc Nephrol 9:63-71.

Rozen F, Russo C, Banvill D, Zingg HH. 1995. Structure, characterization, and expression of the rat oxytocin receptor gene. Proc Natl Acad Sci USA 92:200-204.

Sariola H, Ekblom P, Henke-Fahle S. 1989. Embryonic neurons as in vitro inducers of differentiation of nephrogenic mesenchyme. Dev Biol 132:271-281.
Schmidt A, J ard S, Dreifuss J J , Triboulet E. 1990. Oxytocin receptors in rat kidney during development. Am J Physiol 259 (Renal Fluid Electrolyte Physiol 28): F872-F881.

Sikri KL, Foster CL, MacHugh N, Marshall RD. 1981. Localization of Tamm-Horsfall glycoprotein in the human kidney using immunofluorescence and immuno-electron microscopical techniques. J Anat 132(Pt 4):597-605.

Taugner R, Hackenthal E, Inagami T, Nobiling R, Poulsen K. 1982. Vascular and tubular renin in the kidneys of mice. Histochemistry 75:473-484.

Yu H, Papa F, Sukhatme VP. 1994. Bovine and rodent Tamm-Horsfall protein (THP) genes: Cloning, structural analysis, and promoter identification. Gene Expression 4:63-75. 